\title{
Total Triterpenoid Extraction from Inonotus Obliquus Using Ionic Liquids and Separation of Potential Lactate Dehydrogenase Inhibitors via Ultrafiltration High-Speed Countercurrent Chromatography
}

\author{
Yueqi Wang ${ }^{1,2}$, Liping Guo ${ }^{1, *}$, Chunming Liu ${ }^{2}$, Yuchi Zhang ${ }^{2}$ and Sainan $\mathrm{Li}^{2}$ \\ 1 Faculty of Chemistry, Northeast Normal University, No. 5268 Renmin Street, Nanguan District, \\ Changchun 130024, China; wanglq022@nenu.edu.cn \\ 2 China Central Laboratory, Changchun Normal University, No. 677 North Changji Road, Erdao District, \\ Changchun 130032, China; ccsf777@163.com (C.L.); zhangyuchi2001@163.com (Y.Z.); \\ sainan_85@163.com (S.L.) \\ * Correspondence: guolp078@nenu.edu.cn; Tel.: +86-431-8509976
}

\section{check for} updates

Citation: Wang, Y.; Guo, L.; Liu, C.; Zhang, Y.; Li, S. Total Triterpenoid Extraction from Inonotus Obliquus Using Ionic Liquids and Separation of Potential Lactate Dehydrogenase Inhibitors via Ultrafiltration High-Speed Countercurrent Chromatography. Molecules 2021, 26, 2467. https://doi.org/10.3390/ molecules26092467

Academic Editor: Luisella Verotta

Received: 30 March 2021

Accepted: 22 April 2021

Published: 23 April 2021

Publisher's Note: MDPI stays neutral with regard to jurisdictional claims in published maps and institutional affiliations.

Copyright: (c) 2021 by the authors. Licensee MDPI, Basel, Switzerland. This article is an open access article distributed under the terms and conditions of the Creative Commons Attribution (CC BY) license (https:// creativecommons.org/licenses/by/ $4.0 /)$.

\begin{abstract}
Extracts of the fungus Inonotus obliquus exhibit cytotoxic properties against different cancers; hence, this fungal species has been extensively studied. This study aimed to extract total triterpenoids from Inonotus obliquus using ionic liquids (ILs) and separate potential lactate dehydrogenase (LDH) inhibitors via ultrafiltration (UF)-high-speed countercurrent chromatography (HSCCC). Total triterpenoids from Inonotus obliquus were extracted by performing a single-factor experiment and employing a central composite design via ultrasonic-assisted extraction (UAE) and heat-assisted extraction (HAE). The extract was composed of 1-butyl-3-methylimidazolium bromide as the IL and methanol as the dispersant. Ultrafiltration-liquid chromatography (UF-LC) was used to rapidly scan the LDH inhibitors and betulin and lanosterol were identified as potential inhibitors. To obtain these target compounds, betulin and lanosterol with the purities of $95.9 \%$ and $97.8 \%$ were isolated from HSCCC within $120 \mathrm{~min}$. Their structures were identified using several techniques, among which IL-HAE was fast and effective. This study reports the extraction of triterpenoids from Inonotus obliquus by IL for the first time. Collectively, the findings demonstrate that UF-LC is an effective tool for screening potential LDH inhibitors from crude extracts of I. obliquus and may help to identify bioactive substances against myocardial infarction, whereas high-purity compounds can be separated via UF-HSCCC.
\end{abstract}

Keywords: Inonotus obliquus; ultrafiltration; liquid chromatography; ultrasonic-assisted extraction; lactate dehydrogenase inhibitor; myocardial infarction

\section{Introduction}

The fungus Inonotus obliquus is mainly distributed in northeastern China, northern Russia, and other cold regions [1,2]. The sclerotium of its fruiting body is nodular (sterile block), sessile, 25-40 cm in diameter, dark gray in appearance, irregularly furrow-marked with a deep crack, and hard and brittle when dry [3]. This fungus can be used as food and medicine for preventing and treating malignant tumors, diabetes, liver diseases, vascular diseases, and acquired immune deficiency syndrome [4,5]. Therefore, I. obliquus has attracted considerable attention from researchers owing to its potential anti-cancer properties. For instance, Baek et al. evaluated its cytotoxic activity against four human lung adenocarcinoma cell lines, each with different p53 statuses. They found that the triterpenoids from I. obliquus have potential therapeutic effects against lung cancer and revealed the molecular basis of their cytotoxic activity against human lung cancer [6]. Furthermore, Kou et al. studied the anti-inflammatory effect of triterpenoids from I. obliquus and reported that all lanostanoids remarkably inhibited nitric oxide (NO) production in 
lipopolysaccharide-stimulated BV-2 microglial cells [7]. In another study, it has been shown that triterpenoids from I. obliquus can confer protection to SH-SY5Y cells against oxidative damage by inhibiting cell apoptosis and by exerting neuroprotective activity against $\mathrm{H}_{2} \mathrm{O}_{2}$ induced cell damage [8].

Triterpenoids are substances with several (generally six) condensed isoprene formed by hydroxyl removal and are essential products of isoprene metabolism [9]. Although most of these are composed of 30 carbon atoms, some have only 27 carbon atoms. These substances are abundant in nature. Triterpenoids, mostly lanoline-type triterpenoids that are synthesized from cyclosqualene with a chair boat chair conformation and often containing the same lanosterol mother nucleus structure, are among the main active components in I. obliquus $[6,10,11]$. Traditional extraction methods such as the organic reagent extraction method are costly and time-consuming [12]. To overcome the limitations of traditional methods, the required amount of organic solvents and extraction time should be reduced, and extraction efficiency should be improved.

Ionic liquids (ILs), also known as "green solvents," have broad-spectrum solubilities and are not volatile, making them promising alternatives to organic solvents [13]. ILs also have good thermal stability and are tasteless, and can be easily recycled [14]. Furthermore, the physical and chemical properties of ILs vary widely depending on their chemical structure [15], and because of numerous possibilities of ILs structures by cation and anion selection, they are widely used in organic biocatalytic syntheses, clean fuel production, and in other applications [16]. However, several studies have shown that ILs can threaten human health and exert adverse environmental effects [17], and their toxicity varies with their structure and physical and chemical properties [18]. Therefore, ILs should be designed with caution considering their structure-ecotoxicity relationships [15]. In the present study, different ILs, and dispersants at varying solid: liquid ratios, concentration of the extraction solution, and extraction times were assessed for triterpenoid extraction from I. obliquus.

Ultrafiltration-liquid chromatography (UF-LC) is particularly advantageous for screening and extracting bioactive compounds because of its small sample size requirement and good reproducibility $[19,20]$. After separation of ligand-receptor complexes from unbound compounds via UF, ligands can be identified by liquid chromatography-mass spectrometry (LC-MS). High-speed countercurrent chromatography (HSCCC) is a liquid-liquid partition chromatography technology widely used to separate and purify natural products [21]. Owing to its stability, good reproducibility, and non-requirement of a solid carrier, the adsorption phenomenon because of a carrier is eliminated. In the present study, HSCCC was used to separate potential lactate dehydrogenase (LDH) inhibitors from I. obliquus [12,21].

\section{Results and Discussion}

2.1. Single-Factor Experiments

\subsubsection{Differences in Total Triterpenoid Content Extracted Using Seven IL Types}

Because ILs are composed of cations and anions, the length of the alkyl chain and the composition of anions influence their physical and chemical properties and the extraction efficiency of analytes. Methanol $(\mathrm{MeOH})$ was selected as the dispersant to study the effect of seven ILs (Figure 1) on the total triterpenoids of I. obliquus. Four types of imidazole ILs with different carbon-chain lengths (1-ethyl-3-methylimidazolium hexafluorophosphate ([EMIM] $\mathrm{PF}_{6}$ ), 1-butyl-3-methylimidazolium hexafluorophosphate ([BMIM] $\left.\mathrm{PF}_{6}\right)$, 1-hexyl-3-methylimidazolium hexafluorophosphate ([HMIM] $\left.\mathrm{PF}_{6}\right)$, and 1octyl-3-methylimidazolium hexafluorophosphate $\left(\left[\mathrm{OMIM} \mathrm{PF}_{6}\right)\right)$ and ILs with similar cation and anion compositions (1-butyl-3-methylimidazolium trifluoromethyl sulfonate ([BMIM]TfO, 1-butyl-3-methylimidazolium tetrafluoroborate ([BMIM] $\left.\mathrm{BF}_{4}\right)$, 1-butyl-3-methylimidazolium bromide ([BMIM]Br), and [BMIM] $\mathrm{PF}_{6}$ ) were investigated. 
<smiles>C=[PH](=O)([O-])C(F)(F)F</smiles>

1-butyl-3-methylimidazolium trifluoromethyl sulfonate ([BMIM]TfO)<smiles>CCCCn1cc[n+](C)c1</smiles>

1-butyl-3-methylimidazolium tetrafluoroborate ([BMIM]BF 4 )<smiles>CCCCn1cc[n+](C)c1</smiles>

1-butyl-3-methylimidazolium bromide ([BMIM]Br)<smiles>CCCCn1cc[n+](C)c1</smiles>

1-butyl-3-methylimidazolium hexafluorophosphate ([BMIM] $\mathrm{PF}_{6}$ )<smiles>CCn1cc[n+](C)c1</smiles>

$\mathrm{PF}_{6}{ }^{-}$ hexafluorophosphate ([EMIM] $\mathrm{PF}_{6}$ )<smiles>CCCn1cc[n+](C)c1</smiles>

1-hexyl-3-methylimidazolium hexafluorophosphate $\left(\left[\mathrm{HMIM}_{\mathrm{P}} \mathrm{PF}_{6}\right)\right.$<smiles>CCCCC[n+]1ccn(C)c1</smiles>

1-octyl-3-methylimidazolium hexafluorophosphate ([OMIM]PF ${ }_{6}$ )

Figure 1. Chemical structures of the seven types of ionic liquids.

Under the same extraction conditions, the amounts of total triterpenoids obtained after performing ultrasonic-assisted extraction (UAE) were as follows: $9.45 \mathrm{mg}$ [EMIM]PF 6 , $9.73 \mathrm{mg}$ [BMIM] $\mathrm{PF}_{6}, 3.21 \mathrm{mg}$ [HMIM]PF 6 , and $3.18 \mathrm{mg}$ [OMIM]PF 6 . The amounts of total triterpenoids obtained after performing heat-assisted extraction (HAE) were as follows: $10.12 \mathrm{mg}$ [EMIM]PF 6 , $10.31 \mathrm{mg}$ [BMIM] $\mathrm{PF}_{6}, 4.10 \mathrm{mg}$ [HMIM] PF 6 , and $4.05 \mathrm{mg}$ [OMIM] $\mathrm{PF}_{6}$ (Figure 2A). These data show that when anions are the same, the total triterpenoid content first increases and then decreases with increasing carbon chain length regardless of using UAE or HAE. This may be because with increasing carbon chain length, the viscosity of ILs gradually increases, and the effective components cannot be extracted by using the overly viscous ILs. The extraction effect of [BMIM] $\mathrm{PF}_{6}$ was the strongest; hence, by using the same cation $\left([\mathrm{BMIM}]^{+}\right)$, the extraction effect of different anions $\left(\mathrm{TfO}^{-}, \mathrm{BF}_{4}{ }^{-}, \mathrm{Br}^{-}\right.$, $\mathrm{PF}_{6}{ }^{-}$) was studied. The results showed that [BMIM] Br exerted the best extraction effect (Figure 2A).

A

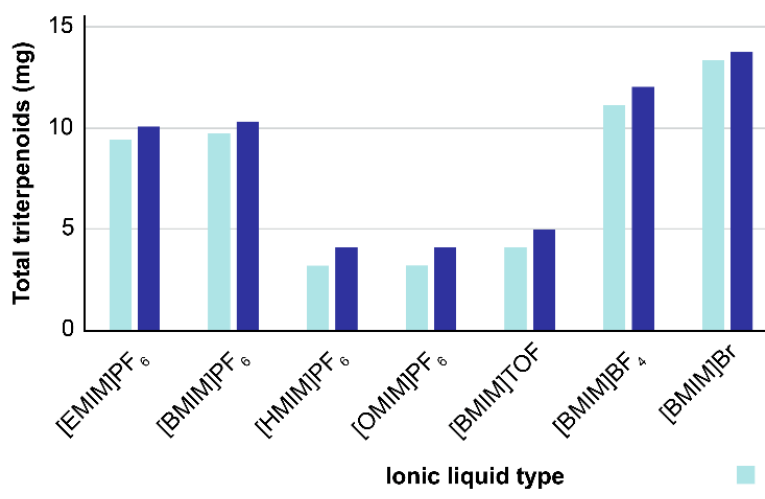

B

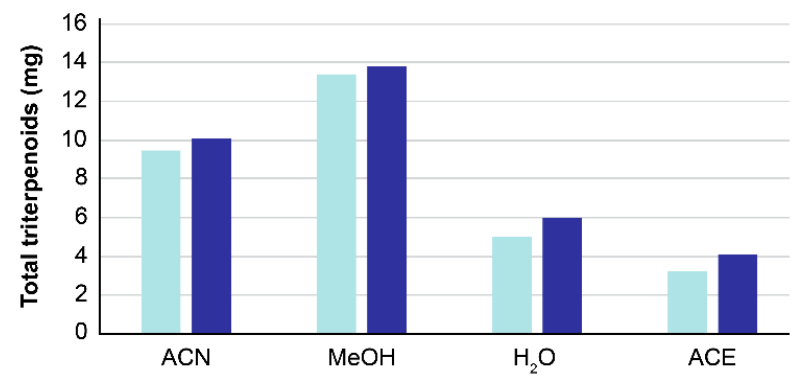

UAE $\square \mathrm{HAE}$

Dispersant type

Figure 2. (A) Effect of different ionic liquid (IL)-methanol extracts on total triterpenoids. (B) Effect of different dispersants on total triterpenoids, with IL $=[\mathrm{BMIM}] \mathrm{Br}$. 


\subsubsection{Effect of Dispersant Type on Total Triterpenoid Content}

[BMIM] Br was selected to investigate the effect of different dispersants, namely, ACN, $\mathrm{MeOH}, \mathrm{H}_{2} \mathrm{O}$, and $\mathrm{ACE}$, on the extraction capacity. The total triterpenoid content using these dispersants and UAE was $9.45,13.40,5.01$, and $3.25 \mathrm{mg}$, respectively. Using HAE, the total triterpenoid content was $10.11,13.80,6.02$, and $4.11 \mathrm{mg}$, respectively. The extraction capacity was the highest with [BMIM] $\mathrm{Br}$ as IL and $\mathrm{MeOH}$ as a dispersant (Figure 2B). Therefore, this IL/dispersant combination was used for follow-up experiments.

\subsection{Effects of the Central Composite Design}

According to the principles of the "central composite test reagent, the experiments were arranged in the form of codes; the codes were obtained based on the actual operation value, and the difference between any two physical quantities was equal to the difference between the corresponding codes. By establishing relevant model fitting effects and factors, the three-dimensional effect surface could be visualized, and the best extraction process was quickly obtained based on the surface area with the best effect.

Experimental results of the central composite design using two extraction methods are shown in Table 1. The three factors (A, solid-liquid ratio; B, concentration of the extraction solution; and $C$, extraction time) were fitted using the total triterpenoid content as the evaluation index. The fitting equations of UAE and HAE are shown in Table 2. The fitting degree of each equation was good (high $R^{2}$ values), and thus, they were used to analyze and predict the extraction process. The results of the binomial fitting analysis of variance (Table 2) showed that the total model equation was significant $(p<0.05)$, indicating that the model had a good fit and a small experimental error, both of which are valuable for accurate predictions. Furthermore, this model was also used to predict and optimize the solid: liquid ratio, concentration of the extraction solution, and extraction time. The $p$-value showed that the primary term of factors $\mathrm{B}, \mathrm{AB}$, and $\mathrm{BC}$ in $\mathrm{UAE}$ and factor $\mathrm{A}$ in HAE had a significant effect on the comprehensive score $(p<0.05)$, whereas the other elements had no significant effect on the result $(p>0.05)$. As the extraction effect was better for HAE than for UAE, HAE was used for subsequent analyses. According to the established polynomial model, through Design-Export 10.0 software statistics, factors A, B, and C were drawn to create the corresponding surface map (Figure 3 ). The area of each factor has been optimized in the figure, and the following conditions for extracting total triterpenoids from I. obliquus were determined for HAE: extraction solution, [BMIM] Br with $\mathrm{MeOH}$; concentration of the extraction solution, $1.0 \mathrm{~mol} / \mathrm{L}$; solid: liquid ratio, 1:30; and extraction time, $83.64 \mathrm{~min}$.
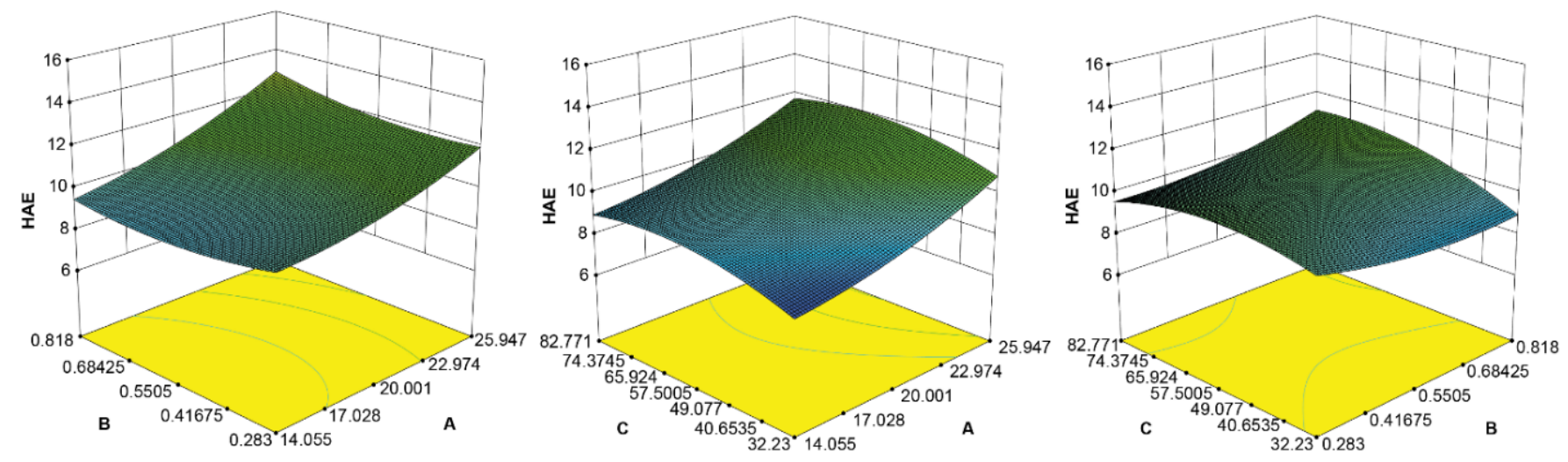

Figure 3. Response surface of the effect of solid: liquid ratio, concentration of the extraction solution (mol/L), and extraction time (min) on total triterpenoids. HAE: heat-assisted extraction; A: solid: liquid ratio; B: concentration of the extraction solution; C: extraction time. 
Table 1. Central composite design and indicator results.

\begin{tabular}{cccccc}
\hline & & Factor & & \multicolumn{2}{c}{ Total Triterpenoids (mg) } \\
\cline { 2 - 6 } No. & $\mathbf{A}$ & $\mathbf{B}$ & $\mathbf{C}$ & UAE & HAE \\
\hline 1 & 0 & 0 & 0 & 8.708 & 10.090 \\
2 & +1.682 & 0 & 0 & 8.500 & 15.446 \\
3 & 0 & 0 & 0 & 8.708 & 10.090 \\
4 & 0 & -1.682 & 0 & 4.285 & 12.301 \\
5 & -1 & -1 & -1 & 8.271 & 9.147 \\
6 & 0 & 0 & 0 & 8.708 & 10.090 \\
7 & 0 & +1.682 & 0 & 8.846 & 12.716 \\
8 & -1.682 & 0 & 0 & 6.220 & 9.537 \\
9 & +1 & +1 & -1 & 7.523 & 10.569 \\
10 & -1 & -1 & +1 & 7.492 & 7.979 \\
11 & -1 & +1 & +1 & 9.536 & 9.147 \\
12 & -1 & +1 & -1 & 7.590 & 7.395 \\
13 & 0 & 0 & +1.682 & 6.911 & 10.781 \\
14 & +1 & +1 & +1 & 11.823 & 11.823 \\
15 & 0 & 0 & 0 & 8.708 & 10.090 \\
16 & +1 & -1 & +1 & 5.016 & 9.852 \\
17 & 0 & 0 & 0 & 8.708 & 10.090 \\
18 & 0 & 0 & 0 & 8.708 & 10.090 \\
19 & +1 & -1 & -1 & 6.270 & 10.569 \\
20 & 0 & 0 & -1.682 & 5.943 & 7.602 \\
\hline
\end{tabular}

A: solid-liquid ratio; B: concentration of the extraction solution; C: extraction time.

\subsection{Process Parameter Optimization and Model Validation}

To verify the reliability of the model, the experiment was performed according to the optimized extraction conditions described in Section 3.2. Under the same conditions, the total triterpene amounts extracted from $1 \mathrm{~g}$ of I. obliquus were $16.81,16.79$, and $16.75 \mathrm{mg}$, respectively. Compared with the predicted value of $16.96 \mathrm{mg}$, the relative deviations were as less as $0.88,1.00$, and $1.24 \%$, respectively, indicating that the mathematical model has good predictability.

\subsection{Evaluation of the Potential Inhibitory Activity of $\mathrm{LDH}$}

The potential LDH inhibitors in I. obliquus were screened using UF-LC. The enzymeligand complexes were separated from the small unconjugated molecules through the UF membrane. The binding of I. obliquus at $50 \mathrm{mg} / \mathrm{mL}$ to $\mathrm{LDH}$ at different concentrations was evaluated, and two compounds were considered as potential LDH ligand compounds (Figure 4). The retention time of compound 1 was $17.98 \mathrm{~min}$, and the inhibition rates of 5, 10 , and $20 \mathrm{U} / \mathrm{mL} \mathrm{LDH}$ were $23.38,39.06$, and $54.58 \%$, respectively. For compound 2 , the retention time was $26.17 \mathrm{~min}$, and the inhibition rates at 5, 10, and $20 \mathrm{U} / \mathrm{mL} \mathrm{LDH}$ were $27.72,48.45$, and $69.44 \%$, respectively. Because compounds 1 and 2 had potent inhibitory effects on LDH, HSCCC was used to separate them. 


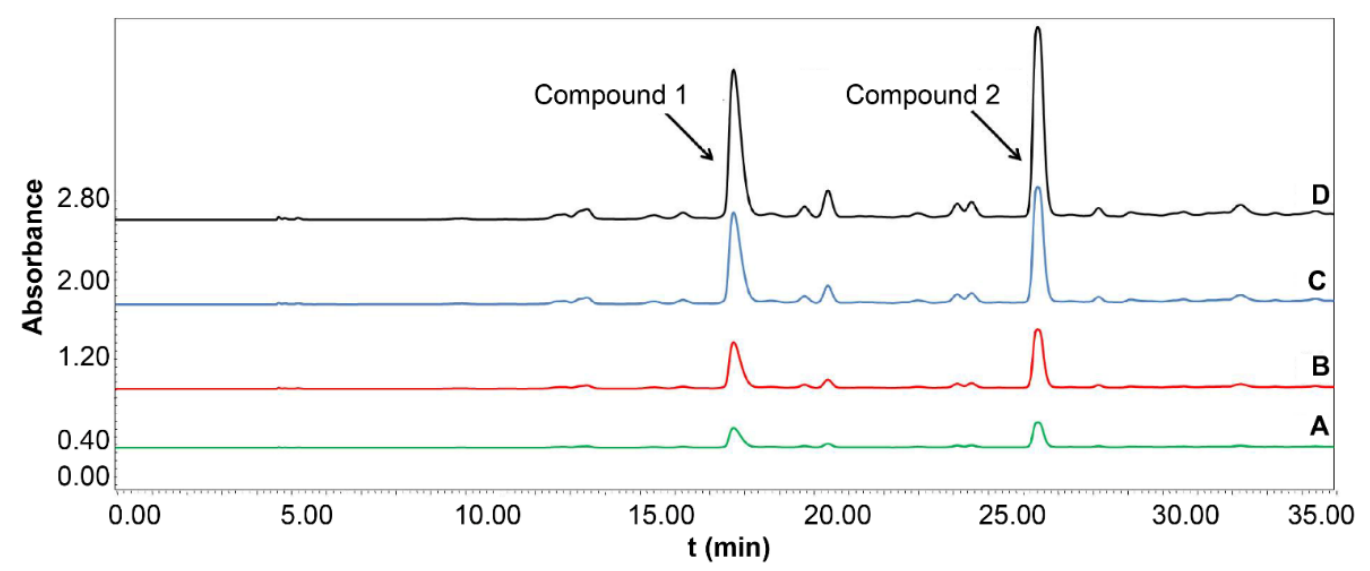

Figure 4. Ultrafiltration high-performance liquid chromatography chromatograms of the lactate dehydrogenase (LDH) inhibitors present in the crude sample of Inonotus obliquus (detection wavelength: $300 \mathrm{~nm}$ ). (A) $20 \mathrm{U} / \mathrm{mL} \mathrm{LDH}$ (B) $10 \mathrm{U} / \mathrm{mL}$ LDH; (C) 5 U/mL LDH; (D) blank.

Table 2. Analysis of variance of the quadratic multiple regression equation.

\begin{tabular}{|c|c|c|c|c|c|c|}
\hline Source & Sum of Squares & Df & Mean Square & F Value & $p$ & Significant \\
\hline \multicolumn{7}{|l|}{ UAE } \\
\hline Model & 45.82 & 9 & 5.09 & 5.35 & 0.0075 & Significant \\
\hline A-Solid:liquid ratio & 0.18 & 1 & 0.18 & 0.19 & 0.6711 & \\
\hline $\begin{array}{l}\text { B-Concentration of the } \\
\text { extraction solution }\end{array}$ & 21.4 & 1 & 21.4 & 22.47 & 0.0008 & \\
\hline C-Extracting time & 2.5 & 1 & 2.5 & 2.62 & 0.1363 & \\
\hline $\mathrm{AB}$ & 5.61 & 1 & 5.61 & 5.89 & 0.0357 & \\
\hline $\mathrm{AC}$ & 0.44 & 1 & 0.44 & 0.46 & 0.5114 & \\
\hline $\mathrm{BC}$ & 8.57 & 1 & 8.57 & 9 & 0.0133 & \\
\hline $\mathrm{A}^{2}$ & 0.62 & 1 & 0.62 & 0.66 & 0.4372 & \\
\hline $\mathrm{B}^{2}$ & 3.45 & 1 & 3.45 & 3.62 & 0.0863 & \\
\hline$C^{2}$ & 4.17 & 1 & 4.17 & 4.38 & 0.0628 & \\
\hline Residual & 9.52 & 10 & 0.95 & & & \\
\hline Lack of Fit & 9.52 & 5 & 1.9 & & & \\
\hline Pure Error & 0 & 5 & 0 & & & \\
\hline Cor Total & 55.34 & 19 & & & & \\
\hline $\begin{array}{c}\text { Fitting equations } \\
\text { HAE }\end{array}$ & \multicolumn{6}{|c|}{$Y=8.67+0.12 A+1.25 B+0.43 C+0.84 A B+0.23 A C+1.03 B C-0.21 A^{2}-0.49 B^{2}-0.54 C^{2}\left(R^{2}=0.8279\right)$} \\
\hline Model & 48.57 & 9 & 5.4 & 3.54 & 0.0308 & \multirow[t]{14}{*}{ Significant } \\
\hline A-Solid-liquid ratio & 26.66 & 1 & 26.66 & 17.49 & 0.0019 & \\
\hline $\begin{array}{l}\mathrm{B}-\text {-Concentration of } \\
\text { the extraction solution }\end{array}$ & 0.32 & 1 & 0.32 & 0.21 & 0.6575 & \\
\hline C-Extracting time & 3.06 & 1 & 3.06 & 2.01 & 0.1868 & \\
\hline $\mathrm{AB}$ & 0.82 & 1 & 0.82 & 0.54 & 0.4812 & \\
\hline $\mathrm{AC}$ & $2.76 \times 10^{-4}$ & 1 & $2.76 \times 10^{-4}$ & $1.81 \times 10^{-4}$ & 0.9895 & \\
\hline $\mathrm{BC}$ & 2.99 & 1 & 2.99 & 1.96 & 0.1916 & \\
\hline $\mathrm{A}^{2}$ & 2.85 & 1 & 2.85 & 1.87 & 0.2015 & \\
\hline $\mathrm{B}^{2}$ & 2.93 & 1 & 2.93 & 1.92 & 0.196 & \\
\hline$C^{2}$ & 7.51 & 1 & 7.51 & 4.93 & 0.0507 & \\
\hline Residual & 15.24 & 10 & 1.52 & & & \\
\hline Lack of Fit & 15.24 & 5 & 3.05 & & & \\
\hline Pure Error & 0 & 5 & 0 & & & \\
\hline Cor Total & 63.81 & 19 & & & & \\
\hline Fitting equations & \multicolumn{6}{|c|}{$\begin{array}{c}Y=10.15+1.40 A+0.15 B+0.47 C+0.32 A B-5.875 e^{-003} A C+0.61 B C+0.44 A^{2}-0.45 B^{2}-0.72 C^{2} \\
\left(R^{2}=0.7611\right)\end{array}$} \\
\hline
\end{tabular}




\subsection{HSCCC Separation of Potential LDH Inhibitors from I. Obliquus}

The separation effect of HSCCC mainly depends on the selection of the solvent system. In the present study, different proportions of $n$-hexane-ethyl acetate-MeOH-water were used as the solvent system. The $K$ values for compounds 1 and 2 , and the resolutions of both compounds, were calculated as described in Section 3.9. The $K$ values of compounds 1 and 2 were calculated as $K=A_{u} / A_{1}$, and their resolution was the ratio of $K_{1}$ to $K_{2}$.

When the $K$ value is in the ideal range (0.5-2.5), the greater the resolution, the better the separation. In the present study, $n$-hexane-ethyl acetate-MeOH-water (5:5:3:7) was used as the solvent system for the separation of compounds 1 and 2, with $K_{1}=1.29, K_{2}=0.99$, and a resolution of 1.30 (Table 3).

Table 3. K values of Inonotus obliquus in different two-phase solvent systems composed of $n$-hexaneethyl acetate- $\mathrm{MeOH}$-water.

\begin{tabular}{|c|c|c|c|}
\hline Solvent System $(v / v)$ & Compound $1\left(K_{1}\right)$ & Compound $2\left(\mathrm{~K}_{2}\right)$ & $\mathrm{K}_{1} / \mathrm{K}_{2}$ \\
\hline 1:1:1:1 & 0.42 & 0.85 & 0.49 \\
\hline $5: 5: 3: 7$ & 1.29 & 0.99 & 1.30 \\
\hline $1: 1: 2: 2$ & 7.58 & 2.73 & 2.78 \\
\hline
\end{tabular}

The mobile phase flow rate determines the retention rate of the stationary phase and the separation of the chromatographic peaks. At a column rotation speed of $850 \mathrm{rpm}$ and a flow rate of $1.0 \mathrm{~mL} / \mathrm{min}$, the retention rate was $72 \%$, and the separation time of $180 \mathrm{~min}$ allowed compounds 1 and 2 to separate. When the flow rate was increased to $2.5 \mathrm{~mL} / \mathrm{min}$, the retention rate was $60 \%$, and the separation time was only $100 \mathrm{~min}$. Although the separation time was shortened, compound 1 could not be separated from other impurity peaks. At a flow rate of $1.5 \mathrm{~mL} / \mathrm{min}$, compounds 1 and 2 were distinctly separated within 120 min with a $68 \%$ retention rate. Hence, the HSCCC separation conditions used were as follows: column rotation, $850 \mathrm{rpm}$; solvent system, $n$-hexane-ethyl acetate-MeOH-water (5:5:3:7); flow rate, $1.5 \mathrm{~mL} / \mathrm{min}$; and injection volume, $100 \mathrm{mg}$ (Figure 5).

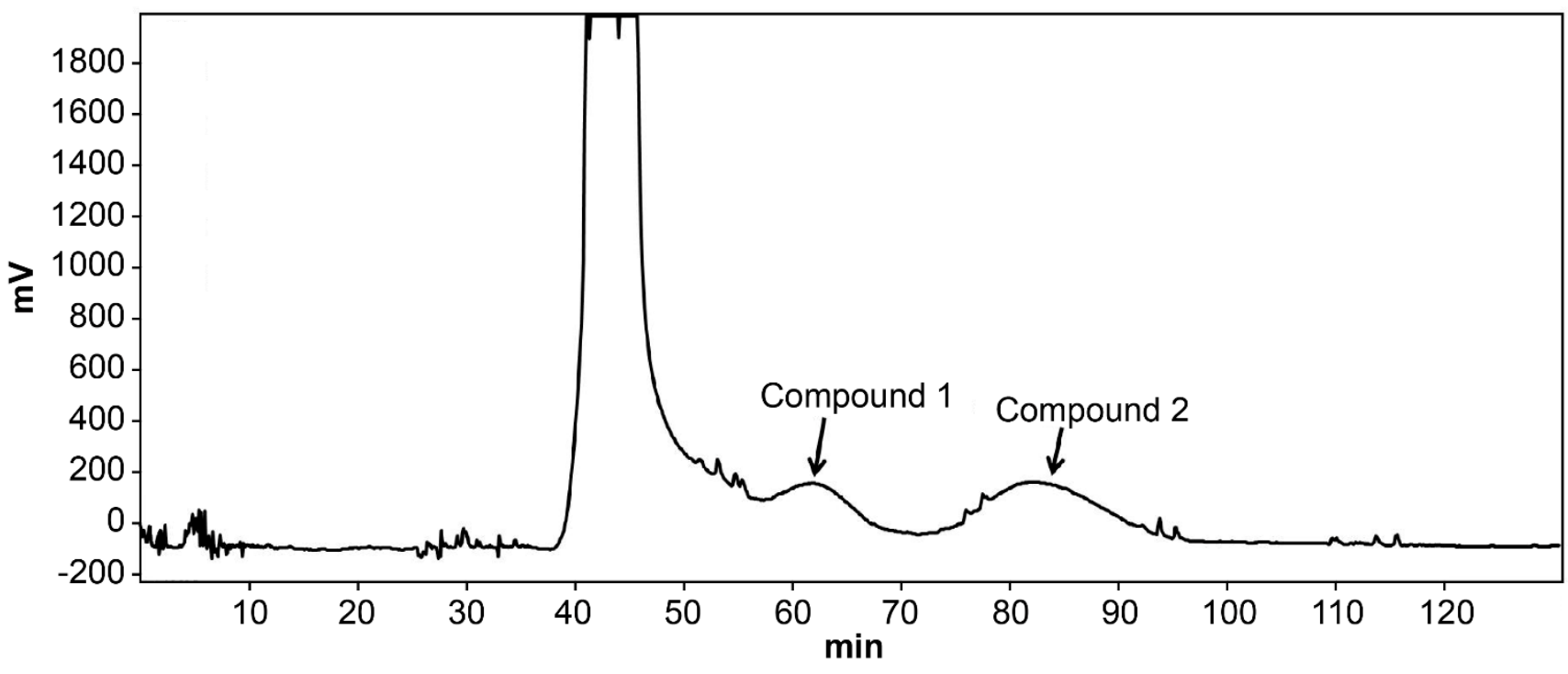

Figure 5. High-speed countercurrent chromatography separation of the crude extract of Inonotus obliquus. n-hexane-ethyl acetate-MeOH-water (5:5:3:7, v/v/v/v); flow rate: $1.5 \mathrm{~mL} / \mathrm{min}$; detection wavelength: $300 \mathrm{~nm}$; rotational speed: $850 \mathrm{rpm}$; sample size: $100 \mathrm{mg}$. 
2.6. Purity Determination and Identification of Potential LDH Inhibitors Using High-Performance Liquid Chromatography (HPLC), Electrospray Ionization-Mass Spectrometry (ESI-MS), ${ }^{1} \mathrm{H}$ Nuclear Magnetic Resonance (NMR), and ${ }^{13} \mathrm{C}$ NMR

Potential LDH inhibitors in I. obliquus extracts were analyzed via HPLC. The purity of compounds 1 and 2 were $95.9 \%$ and $97.8 \%$, respectively (Figure 6 ). In the positive ion mode, the mass spectra of compounds 1 and 2 were recorded. Compounds 1 and 2 were identified as betulin and lanosterol, respectively, based on their HPLC retention times, MS/MS data, as well as ${ }^{1} \mathrm{H}$ and ${ }^{13} \mathrm{C}$ NMR data [22,23]. The chemical structures of betulin and lanosterol are shown in Figure 7.

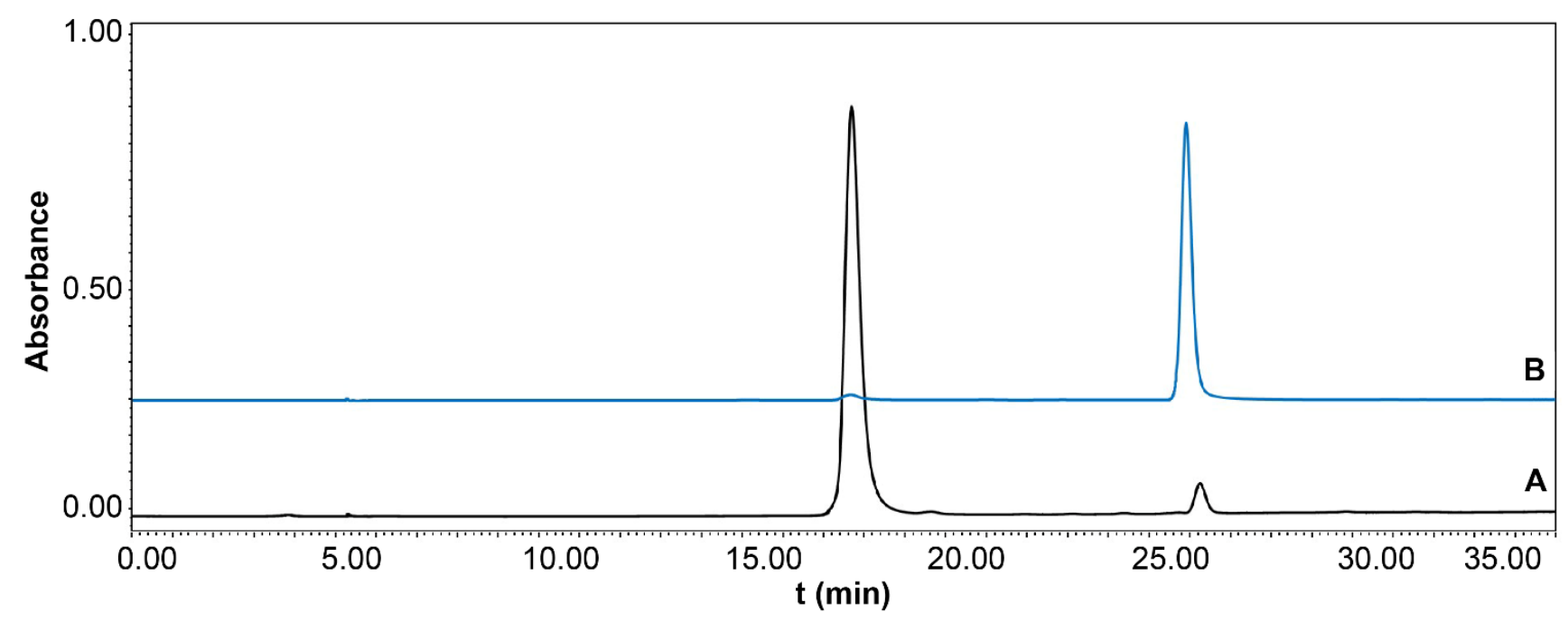

Figure 6. High-performance liquid chromatography chromatograms of compounds 1 and 2. (A) Compound 1, identified as betulin; (B) Compound 2, identified as lanosterol.

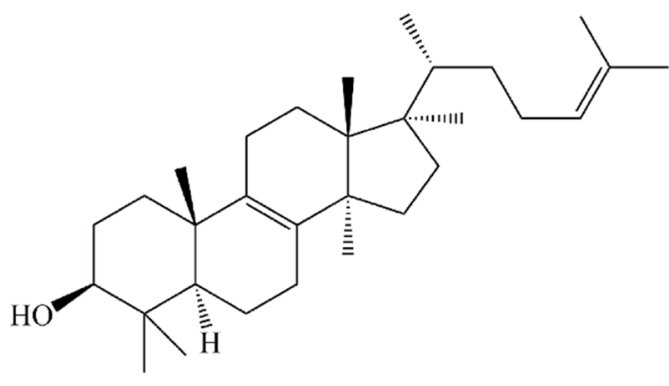

Betulin

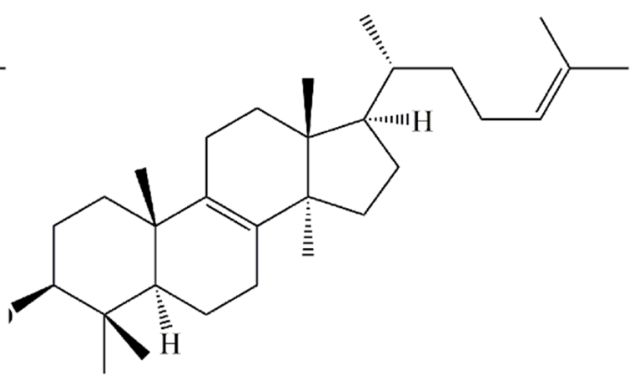

Lanosterol

Figure 7. The chemical structures of betulin and lanosterol.

The study has certain limitations, which can be overcome in the future. First, since some ionic liquids are expensive, it is crucial to perform the least number of experiments to determine the best scheme of ionic liquid extraction in the extraction process. Additionally, studies have shown that long alkyl chain ILs exert toxicity; therefore, the selection and design of ILs should be carefully considered. Second, ultrafiltration liquid chromatography can only be used to detect the inhibitory enzyme activity of compounds in vitro and cannot be used to represent the medicinal effect of compounds in vivo.

\section{Materials and Methods}

\subsection{General Experimental Procedures}

A BS-124S electronic balance (Sartorius, Gottingen, Germany) was used for weight measurements. An ultraviolet-visible spectrophotometer (Thermo Fisher Scientific, San Jose, CA, USA) was used for absorbance measurements. HPLC was conducted on a 
Waters 2695 instrument (DAD, Milford, CT, USA) coupled to a Waters 2998 diode array detector (DAD). A Sigma 1-14 centrifuge (Sigma Zentrifugen, Osterode am Harz, Germany) equipped with an ultra-membrane filter Microcon YM-100 (Millipore, Bedford, MA, USA) was also used. ESI-MS was performed using an LCQ Fleet ion-trap mass spectrometer (Thermo Fisher Scientific, San Jose, CA, USA) equipped with an ESI source (Thermo Fisher Scientific, San Jose, CA, USA). HSCCC was performed on a TBE-300B Spectrum HSCCC (Shanghai Tauto Biotech Co., Ltd., Shanghai, China). ${ }^{1} \mathrm{H}$ and ${ }^{13} \mathrm{C}$ NMR spectra were recorded on a Bruker AV-400 and Avance-600 spectrometer (Bruker BioSpin, Ettlingen, Germany).

\subsection{Chemicals and Reagents}

HPLC-grade MeOH for HPLC and LC-MS was purchased from Fisher Scientific (UK). Ultra-pure water $(18.2 \mathrm{M} \Omega-\mathrm{cm})$ was produced using a Milli-Q water purification system (Millipore, Burlington, MA, USA). LDH was obtained from Sigma-Aldrich (St. Louis, MO, USA), and phosphate-buffered saline (PBS) from Bueke (Switzerland). All organic solvents used for I. obliquus extraction and HSCCC separation were of analytical grade and purchased from Beijing Chemical Works (Beijing, China). The I. obliquus specimen used for extraction was stored in the Central Laboratory of Changchun Normal University, China (voucher specimen number: CCSFU-W1702). All ILs, vanillin, oleanolic acid, and acid standards were purchased from Shanghai Aladdin Biochemical Technology Co., Ltd. (Shanghai, China).

\subsection{Determination of Total Triterpenoids}

The total triterpenoid content was determined via vanillin-glacial acetic acid-perchloric acid spectrophotometry using oleanolic acid as the standard. Oleanolic acid (10 mg) was dissolved in $\mathrm{MeOH}$ in a $50-\mathrm{mL}$ flask to prepare a $0.2 \mathrm{mg} / \mathrm{mL}$ standard solution. Standard solutions $(0.0-0.7 \mathrm{~mL})$ in test tubes were evaporated in a $90{ }^{\circ} \mathrm{C}$ water bath. Thereafter, $0.3 \mathrm{~mL} 5 \%$ vanillin-glacial acetic acid solution and $1 \mathrm{~mL}$ perchloric acid were added to each tube and mixed evenly. After $20 \mathrm{~min}$ in a water bath at $60^{\circ} \mathrm{C}$, mixtures were rapidly cooled to room temperature $\left(25^{\circ} \mathrm{C}\right)$ with cold water, diluted with glacial acetic acid in a 10-mL flask, and shaken. The absorbance ( $\mathrm{Y}$, ordinate) of each mixture was measure at $550 \mathrm{~nm}$ and plotted against the mass ( $\mathrm{X}$, abscissa) of oleanolic acid. The total triterpenoid content was obtained in mg oleanolic acid per gram of dried I. obliquus.

\subsection{Extraction of ILS}

\subsubsection{UAE}

Seven types of ILs and four dispersants were used as extraction solutions. Four types of ILs with different carbon-chain lengths were selected: [EMIM] $\mathrm{PF}_{6}$, [BMIM] $\mathrm{PF}_{6}$, $[\mathrm{HMIM}] \mathrm{PF}_{6}$, and [OMIM] $\mathrm{PF}_{6}$; ILs with similar cation and anion compositions were also investigated: $[\mathrm{BMIM}] \mathrm{TfO},[\mathrm{BMIM}] \mathrm{BF}_{4},[\mathrm{BMIM}] \mathrm{Br}$, and $[\mathrm{BMIM}] \mathrm{PF}_{6}$. The four dispersants were $\mathrm{MeOH}$, acetonitrile $(\mathrm{ACN}), \mathrm{H}_{2} \mathrm{O}$, and acetone (ACE) (Kunshan Ultrasonic Instrument Co., Ltd., Kunshan, China). The concentration of extraction solutions (0.1-1.0 mol/L), duration of extraction (15-100 $\mathrm{min}$ ), and solid: liquid ratio (1:10-1:30) varied for extracting triterpenoids from $1 \mathrm{~g}$ of I. obliquus. During the preliminary screening, when the solid: liquid ratio increased from 1:30 to 1:40, the total triterpenoid content of I. obliquus did not increase significantly. To optimize solvent usage, 1:30 was selected as the maximum solid: liquid ratio. When the concentration of the extract increased from $1.0 \mathrm{~mol} / \mathrm{L}$ to $1.2 \mathrm{~mol} / \mathrm{L}$, the total triterpenoid content of I. obliquus decreased, and when the concentration of the extraction solution was too low, the ILs could not be fully utilized; hence, a concentration of the extraction solution range from $0.1 \mathrm{~mol} / \mathrm{L}$ to $1.0 \mathrm{~mol} / \mathrm{L}$ was selected. Furthermore, the total triterpenoid content of I. obliquus decreased slightly at $110 \mathrm{~min}$ and greatly after 120 and $150 \mathrm{~min}$ [24]. UAE was performed using a $750 \mathrm{~W}$ ultrasonic processor (BS-250; Kunshan Ultrasonic Instrument, Co., Ltd., Kunshan, China) at 80\% amplitude [25] and $31^{\circ} \mathrm{C}$. Because ultrasonic waves increase the solvent temperature, ice coating was used 
to control the temperature during the extraction process. The extracts were centrifuged at $10,000 \times g$ for $5 \mathrm{~min}$; then, $0.1 \mathrm{~mL}$ of the supernatant was evaporated until dryness in a water bath at $60^{\circ} \mathrm{C}$, and a post-treatment test was conducted as described below. All the samples were prepared and analyzed in triplicate [26].

\subsubsection{HAE}

Total triterpenoids were also extracted from I. obliquus via HAE, and the factor level was consistent with that of UAE. In our preliminary screening, the total triterpenoid yield gradually increased with increasing temperature; therefore, $70^{\circ} \mathrm{C}$ was selected as the $\mathrm{HAE}$ temperature [27] and the extract treatment was the same as that used for UAE.

\subsection{Process Level Screening}

\subsubsection{Single-Factor Experiment}

Effect of IL Type on Total Triterpenoid Extraction

When the solid: liquid ratio was 1:10, the concentration of the extraction solution was $0.6 \mathrm{~mol} / \mathrm{L}$, extraction time was $80 \mathrm{~min}$, and dispersant was $\mathrm{MeOH}$. Different extraction solutions containing seven types of ILs ([BMIM] TfO, [BMIM] BF4, [BMIM] Br, [BMIM] $\mathrm{PF}_{6}$, $[\mathrm{EMIM}] \mathrm{PF}_{6},[\mathrm{HMIM}] \mathrm{PF}_{6}$, and $\left[\mathrm{OMIM}_{\mathrm{PF}}\right.$ ) were examined. The index of total triterpenoids per gram of I. obliquus was evaluated in all experiments. The extraction ability of different IL components in UAE and HAE was evaluated. The highest extraction yield was obtained by using [BMIM] Br. All samples were prepared and analyzed in triplicate.

Effect of Dispersant Type on Total Triterpenoids

Using $1 \mathrm{~g}$ of I. obliquus at a 1:10 solid: liquid ratio, the concentration of the extraction solution was $0.6 \mathrm{~mol} / \mathrm{L}$, extraction time was $80 \mathrm{~min}$, and IL was [BMIM] Br. The extraction ability of different dispersants $\left(\mathrm{ACN}, \mathrm{MeOH}, \mathrm{H}_{2} \mathrm{O}\right.$, and $\mathrm{ACE}$ ) was investigated using UAE and HAE. The results showed that when the dispersant was $\mathrm{MeOH}$, the extraction yield was the highest.

\subsubsection{Optimization of the Central Composite Design}

I. obliquus ( $1 \mathrm{~g}$ ) was extracted with a solution composed of [BMIM] $\mathrm{Br}$ as the IL and $\mathrm{MeOH}$ as the dispersant. Different solid: liquid ratios (1:10-1:30), concentration of the extraction solution $(0.1-1.0 \mathrm{~mol} / \mathrm{L})$, and extraction times (15-100 $\mathrm{min}$ ) were evaluated using the central composite design. There were five levels for each factor. The minimum level was set as -1.682 and the maximum as +1.682 ; other levels $(-1,0$, and +1$)$ were calculated using Equation (1).

$$
\frac{-1-(-11.682)}{x-10}=\frac{1.682-(-1.682)}{30-10} .
$$

For example, for factor $\mathrm{A}:-1.682$ is 10 and +1.682 is 30 ; if the level of $\mathrm{A}$ is -1 , the value is $x$, and the value of $x$ is obtained by Equation (1). The levels of the different factors are shown in Table 4.

The total triterpenoid content in each experimental group was determined using the central composite design, and the experimental data for each group were fitted and analyzed. The experimental scheme and results are shown in Table 1. The same experimental conditions were repeated six times to verify the central point of the experiment, and the results were used to investigate the error of the model. Using Design-Expert 10.0 software (Stat-Ease, Minneapolis, MN, USA) for UAE and HAE statistical analyses, the effect surface map of the two factors in the model was drawn to each evaluation index. The model often reflected the change in the response value with a smaller error, had a significant impact, and better analyzed and predicted the extraction process, based on which optimal scheme was selected. 
Table 4. Factors and levels of the central composite design.

\begin{tabular}{cccccc}
\hline Factor & \multicolumn{5}{c}{ Level } \\
\hline & -1.682 & -1 & 0 & +1 & +1.682 \\
A (solid-liquid ratio) & 10 & 14.055 & 20 & 25.945 & 30 \\
B (concentration of the & 0.1 & 0.282 & 0.55 & 0.818 & 1 \\
extraction solution, mol/L) & 15 & 32.232 & 57.5 & 82.767 & 100 \\
C (extracting time, min) & 15 & &
\end{tabular}

\subsection{Statistical Analysis}

Design-Expert 10.0 software was used to analyze the extraction conditions of triterpenoids from I. obliquus.

\subsection{Determination of the Potential Inhibitory Activity of $L D H$}

The potential LDH-inhibitory activity of I. obliquus was determined by UF-LC. The ultrafiltration process included culture, washing, and separation [28]. I. obliquus extract $(50 \mathrm{mg})$ was dissolved in $50 \% \mathrm{MeOH}(1 \mathrm{~mL})$ and filtered using a $0.45-\mu \mathrm{m}$ membrane. The filtrate $(10 \mu \mathrm{L} ; 50 \mathrm{mg} / \mathrm{mL})$, PBS (pH 7.4; $100 \mu \mathrm{L})$, and LDH $(90 \mu \mathrm{L} ; 5,10$, and $20 \mathrm{U} / \mathrm{mL})$ were mixed evenly. LDH was replaced with $90 \mu \mathrm{L}$ PBS in the blank solution. All the four groups (blank, 5, 10, and $20 \mathrm{U} / \mathrm{mL} \mathrm{LDH}$ ) were incubated at $37^{\circ} \mathrm{C}$ for $30 \mathrm{~min}$. The mixture was then centrifuged at $10,000 \times g$ and $25^{\circ} \mathrm{C}$ for $10 \mathrm{~min}$ with an ultrafiltration membrane (molecular weight cut-off, $100 \mathrm{kDa}$ ) to remove any unbound compounds. Thereafter, $100 \mu \mathrm{L}$ $\mathrm{MeOH}$ : water mixture (50:50, $v / v, \mathrm{pH} 3.3)$ was added to the UF membrane and centrifuged at $10,000 \times g$ for $10 \mathrm{~min}(\times 3)$ to release the bound ligand [29]. The LDH inhibition rate was calculated using the equation $(\mathrm{Aa}-\mathrm{Ab}) / \mathrm{Aa} \times 100 \%$, where $\mathrm{Aa}$ and $\mathrm{Ab}$ are the absorbances of the blank and the experimental group, respectively [30]. Finally, the solvent was removed under vacuum, and the released ligand was used for further analyses.

\subsection{High-Performance Liquid Chromatography-Diode Array Detector-Mass Spectrometry (HPLC-DAD-MS) Analysis}

The HPLC-DAD-MS technique was used to analyze the I. obliquus extract. A Waters $2695 \mathrm{C}_{18}$ column $(250 \times 4.6 \mathrm{~mm}, 5 \mu \mathrm{m})$ was used with a $\mathrm{MeOH}(\mathrm{A})$ and water (B) mobile phase at a $0.5 \mathrm{~mL} / \mathrm{min}$ flow rate. The elution procedure was as follows: 0-30 $\mathrm{min}, 24-56 \%$ solvent A; 30-35 min, 56-76\% solvent A. Online ultraviolet spectra were detected at $300 \mathrm{~nm}$. An LCQ Fleet ion-trap mass spectrometer was connected to the photo-diode array instrument by an ESI interface and used to perform the MS and MS ${ }^{\mathrm{n}}$ analyses. The mass spectrometer was operated in the positive ion mode, and the flow rate was $0.15 \mathrm{~mL} / \mathrm{min}$. The capillary voltage was set at $-20 \mathrm{~V}$ in the positive ion mode. A full scan was performed using selected reaction monitoring mode-based identification at $4.5 \mathrm{kV}$ spray voltage, $350{ }^{\circ} \mathrm{C}$ capillary temperature, and 10 psi pressure. A $100-1200 \mathrm{~m} / \mathrm{z}$ scan range at a resolution of 17,500 was employed.

\subsection{Separation of LDH Inhibitors by HSCCC}

According to the partition coefficient $(K)$ and the resolution of target compounds (compounds 1 and 2), the HSCCC two-phase solvent system was selected. The two-phase solvent system was thoroughly mixed at $25^{\circ} \mathrm{C}$; then, $10 \mathrm{mg}$ of I. obliquus extract was added, and $2 \mathrm{~mL}$ of each of the upper and lower phases were collected. After the solvent was evaporated, the phases were analyzed using HPLC. Under the same operating conditions, the peak areas of the upper and lower phases were recorded as $A_{u}$ and $A_{1}$, respectively. The $K$ values of compounds 1 and 2 were calculated as $K=A_{u} / A_{1}$, and their resolution was the ratio of $K_{1}$ to $K_{2}$.

For this study, the stationary phase was the upper phase, and the mobile phase was the lower phase. During each separation process, the coiled column was filled with the stationary phase. Following column rotation at $850 \mathrm{rpm}$ for $30 \mathrm{~min}$, the mobile phase was pumped into the column at a flow rate of $1.5 \mathrm{~mL} / \mathrm{min}$. When the hydrodynamic equilibrium 
was reached, the sample solution $(100 \mathrm{mg}$ ) was injected. The detection wavelength was set at $300 \mathrm{~nm}$, and the eluted compound was collected in the fraction collector. The solvents were then removed from the collected components using a rotary evaporator and analyzed. Following the elution of the required peaks (compounds 1 and 2), the program was stopped, and the stationary phases remaining on the column were collected. It should be noted that the retention rate of the stationary phase is equal to the volume of the stationary phase divided by the total volume of the chromatographic column.

\subsection{Analytical Data for Compounds 1 and 2}

The main features of compounds 1 and 2 are summarized in Table 5.

Table 5. Main features of compounds 1 and 2.

\begin{tabular}{|c|c|c|}
\hline & Compound 1 & Compound 2 \\
\hline Name & Betulin $^{22}$ & Lanosterol $^{23}$ \\
\hline Retention time- $t_{\mathrm{R}(\min )}$ & 17.98 & 26.17 \\
\hline ESI-MS (+) m/z & $442[\mathrm{M}]^{+}$ & $426[\mathrm{M}]^{+}$ \\
\hline Molecular formula & $\mathrm{C}_{30} \mathrm{H}_{50} \mathrm{O}$ & $\mathrm{C}_{30} \mathrm{H}_{50} \mathrm{O}$ \\
\hline${ }^{1} \mathrm{H}-\mathrm{NMR}\left(400 \mathrm{MHz}, \mathrm{CDCl}_{3}\right) \delta$ & $\begin{array}{c}0.75(3 \mathrm{H}, \mathrm{s}, \mathrm{H}-24), 0.82(3 \mathrm{H}, \mathrm{s}, \\
\mathrm{H}-25), 0.96(3 \mathrm{H}, \mathrm{s}, \mathrm{H}-23), 0.97 \\
(3 \mathrm{H}, \mathrm{s}, \mathrm{H}-27), 1.02(3 \mathrm{H}, \mathrm{s}, \\
\mathrm{H}-26), 1.68(3 \mathrm{H}, \mathrm{s}, \mathrm{H}-30), 3.18 \\
(1 \mathrm{H}, \mathrm{dd}, \mathrm{J}=11.2,4.8 \mathrm{~Hz}, \mathrm{H}-3) \\
3.31(1 \mathrm{H}, \mathrm{d}, \mathrm{J}=10.8 \mathrm{~Hz}, \\
\mathrm{H}-28 \alpha), 3.78(1 \mathrm{H}, \mathrm{d}, \mathrm{J}=10.8 \\
\mathrm{Hz}, \mathrm{H}-28 \beta), 4.58(1 \mathrm{H}, \mathrm{s}, \\
\mathrm{H}-29 \alpha), 4.68(1 \mathrm{H}, \mathrm{s}, \mathrm{H}-29 \beta)\end{array}$ & $\begin{array}{c}0.68(3 \mathrm{H}, \mathrm{s}, \mathrm{H}-30), 0.80(3 \mathrm{H}, \mathrm{s}, \\
\mathrm{H}-18), 0.87(3 \mathrm{H}, \mathrm{d}, \mathrm{J}=6.5 \mathrm{~Hz}, \\
\mathrm{H}-21), 0.90(3 \mathrm{H}, \mathrm{s}, \mathrm{H}-28), 0.99 \\
(3 \mathrm{H}, \mathrm{s}, \mathrm{H}-19), 1.03(3 \mathrm{H}, \mathrm{s}, \\
\mathrm{H}-29), 1.60(3 \mathrm{H}, \mathrm{s}, \mathrm{H}-27), 1.68 \\
(3 \mathrm{H}, \mathrm{s}, \mathrm{H}-26), 3.21(1 \mathrm{H}, \mathrm{dd}, \mathrm{J}= \\
\begin{array}{c}3.4,9.3 \mathrm{~Hz}, \mathrm{H}-3), 5.08(1 \mathrm{H}, \mathrm{t}, \mathrm{J} \\
=5.2 \mathrm{~Hz}, \mathrm{H}-24)\end{array}\end{array}$ \\
\hline${ }^{13} \mathrm{C}-\mathrm{NMR}\left(100 \mathrm{MHz}, \mathrm{CDCl}_{3}\right) \delta$ & $\begin{array}{c}38.6(\mathrm{C}-1), 27.3(\mathrm{C}-2), 79.0 \\
(\mathrm{C}-3), 38.8(\mathrm{C}-4), 55.2(\mathrm{C}-5), \\
18.3(\mathrm{C}-6), 34.2(\mathrm{C}-7), 40.9 \\
(\mathrm{C}-8), 50.3(\mathrm{C}-9), 37.1(\mathrm{C}-10), \\
20.8(\mathrm{C}-11), 25.1(\mathrm{C}-12), 37.2 \\
(\mathrm{C}-13), 42.7(\mathrm{C}-14), 27.0(\mathrm{C}-15), \\
29.1(\mathrm{C}-16), 47.7(\mathrm{C}-17), 47.7 \\
(\mathrm{C}-18), 48.7(\mathrm{C}-19), 150.5 \\
(\mathrm{C}-20), 29.7(\mathrm{C}-21), 33.9(\mathrm{C}-22), \\
27.9(\mathrm{C}-23), 15.3(\mathrm{C}-24), 16.1 \\
(\mathrm{C}-25), 15.9(\mathrm{C}-26), 14.7(\mathrm{C}-27), \\
60.5(\mathrm{C}-28), 109.7(\mathrm{C}-29), 19.0 \\
(\mathrm{C}-30)\end{array}$ & $\begin{array}{c}36.3(\mathrm{C}-1), 28.2(\mathrm{C}-2), 79.0 \\
(\mathrm{C}-3), 38.9(\mathrm{C}-4), 50.9(\mathrm{C}-5), \\
21.0(\mathrm{C}-6), 27.8(\mathrm{C}-7), 134.3 \\
(\mathrm{C}-8), 134.3(\mathrm{C}-9), 37.0(\mathrm{C}-10), \\
18.2(\mathrm{C}-11), 26.5(\mathrm{C}-12), 44.4 \\
(\mathrm{C}-13), 49.8(\mathrm{C}-14), 30.9(\mathrm{C}-15), \\
30.8(\mathrm{C}-16), 50.3(\mathrm{C}-17), 15.4 \\
(\mathrm{C}-18), 18.6(\mathrm{C}-19), 36.2(\mathrm{C}-20), \\
19.1(\mathrm{C}-21), 35.3(\mathrm{C}-22), 25.7 \\
(\mathrm{C}-23), 125.2(\mathrm{C}-24), 130.9 \\
(\mathrm{C}-25), 24.9(\mathrm{C}-26), 17.6(\mathrm{C}-27), \\
24.2(\mathrm{C}-28), 27.9(\mathrm{C}-29), 15.7 \\
(\mathrm{C}-30)\end{array}$ \\
\hline
\end{tabular}

\section{Conclusions}

The total triterpenoids in I. obliquus were extracted in UAE and HAE modes using ILs, different anions, and dispersants. [BMIM] Br with $\mathrm{MeOH}$ served as the extraction solution for subsequent analyses. The solid:liquid ratio, concentration of the extraction solution, and extraction time were optimized using the central composite design and verified. The concentration of the extraction solution was $1.0 \mathrm{~mol} / \mathrm{L}$, the solid:liquid ratio was $1: 30$, the extraction time was $83.64 \mathrm{~min}$, and the temperature was $70^{\circ} \mathrm{C}$, in which the highest total triterpene content was obtained from I. obliquus using HAE. Potential LDH inhibitors in I. obliquus were screened via UF-LC-MS and identified as betulin and lanosterol, which were then separated via HSCCC within 120 min with purities of $95.9 \%$ and $97.8 \%$, respectively. Thus, we demonstrated that IL-HAE could be applied for triterpenoid extraction from I. obliquus, and UF-LC-MS is a fast and feasible method for studying the potential medicinal value of these compounds. 
Author Contributions: Conceptualization, data curation, and eriting_original draft preparation, Y.W.; validation and writing_-review and editing, L.G.; funding acquisition, project administration, and writing-review and editing, C.L.; formal analysis, investigation, supervision, and visualization, Y.Z.; resources, software, and methodology, S.L. All authors have read and agreed to the published version of the manuscript.

Funding: This research was funded by the National Natural Science Foundation of China, grant number 31870336; and a team project grant from the Jilin Development and Reform Commission, grant number 2018C0050-2.

Institutional Review Board Statement: Not applicable.

Informed Consent Statement: Not applicable.

Data Availability Statement: The data presented in this study are available in the published article.

Conflicts of Interest: The authors declare no conflict of interest.

Sample Availability: Samples of the compounds are not available from the authors.

\section{References}

1. Zheng, W.; Zhang, M.; Zhao, Y.; Miao, K.; Jiang, H. NMR-based metabonomic analysis on effect of light on production of antioxidant phenolic compounds in submerged cultures of Inonotus obliquus. Bioresour. Technol. 2009, 100, 4481-4487. [CrossRef]

2. Zhao, F.; Mai, Q.; Ma, J.; Xu, M.; Wang, X.; Cui, T.; Qiu, F.; Han, G. Triterpenoids from Inonotus obliquus and their antitumor activities. Fitoterapia 2015, 101, 34-40. [CrossRef]

3. Wang, C.; Chen, Z.; Pan, Y.; Gao, X.; Chen, H. Anti-diabetic effects of Inonotus obliquus polysaccharides-chromium (III) complex in type 2 diabetic mice and its sub-acute toxicity evaluation in normal mice. Food Chem. Toxicol. 2017, 108, 498-509. [CrossRef]

4. Wold, C.W.; Kjeldsen, C.; Corthay, A.; Rise, F.; Christensen, B.E.; Duus, J. Øllgaard; Inngjerdingen, K.T. Structural characterization of bioactive heteropolysaccharides from the medicinal fungus Inonotus obliquus (Chaga). Carbohydr. Polym. 2018, 185, 27-40. [CrossRef] [PubMed]

5. Xu, X.; Wu, P.; Wang, T.; Yan, L.; Lin, M.; Chen, C. Synergistic effects of surfactant-assisted biodegradation of wheat straw and production of polysaccharides by Inonotus obliquus under submerged fermentation. Bioresour. Technol. 2019, 278, 43-50. [CrossRef]

6. Baek, J.; Roh, H.-S.; Baek, K.-H.; Lee, S.; Lee, S.; Song, S.-S.; Kim, K.H. Bioactivity-based analysis and chemical characterization of cytotoxic constituents from Chaga mushroom (Inonotus obliquus) that induce apoptosis in human lung adenocarcinoma cells. J. Ethnopharmacol. 2018, 224, 63-75. [CrossRef] [PubMed]

7. Kou, R.-W.; Han, R.; Gao, Y.-Q.; Li, D.; Yin, X.; Gao, J.-M. Anti-neuroinflammatory polyoxygenated lanostanoids from Chaga mushroom Inonotus obliquus. Phytochemistry 2021, 184, 112647. [CrossRef] [PubMed]

8. Zou, C.X.; Dong, S.H.; Hou, Z.L.; Yao, G.D.; Lin, B.; Huang, X.X.; Song, S.J. Modified lanostane-type triterpenoids with neuroprotective effects from the fungus Inonotus obliquus. Bioorg. Chem. 2020, 105, 104438. [CrossRef]

9. Nikitina, S.; Khabibrakhmanova, V.; Sysoeva, M. Composition and biological activity of triterpenes and steroids from Inonotus obliquus (chaga). Biomeditsinskaya Khimiya 2016, 62, 369-375. [CrossRef]

10. Dehai, L.; Lingjuan, D.; Ning, K.; Jialin, G.; Zhanbin, W. Effect of extraction techniques on the extraction and hypolipidemic activity in vitro of triterpenoids from Inonotus hispidus. Food Sci. 2018, 39, 291-297.

11. Wold, C.W.; Gerwick, W.H.; Wangensteen, H.; Inngjerdingen, K.T. Bioactive triterpenoids and water-soluble melanin from Inonotus obliquus (Chaga) with immunomodulatory activity. J. Funct. Foods 2020, 71, 104025. [CrossRef]

12. Wu, T.; Liu, C.M.; Huang, Y.; Li, S.; Wang, Y. Simultaneous screening and isolation of activated constituents from Puerariae Flos by ultrafiltration with liquid chromatography and mass spectrometry combined with high-speed counter-current chro-matography. J. Sep. Sci. 2018, 41, 4458-4468. [CrossRef]

13. Zhan, X.; Lv, B.; Yang, K.; Jing, G.; Zhou, Z. Dual-Functionalized Ionic Liquid Biphasic Solvent for Carbon Dioxide Capture: High-Efficiency and Energy Saving. Environ. Sci. Technol. 2020, 54, 6281-6288. [CrossRef] [PubMed]

14. Liu, X.; Chen, P.; Wang, L.L.; Wang, C.J.; Zhao, M.Q.; Fu, J.H. Polydimethylsiloxane/ionic liquid sponge used in headspace solid-phase extraction coupled with GC-MS for rapid analysis of essential oil in lavender. Biomed. Chromatogr. 2021, $35,4992$. [CrossRef] [PubMed]

15. Guilherme, J.; F'atima, J.; S'onia, P.M.V.; Fernando, J.M.G.; Jana, A.; Joana, L.P. New insights on the effects of ionic liquid structural changes at the gene expression level: Molecular mechanisms of toxicity in Daphnia magna. J. Hazard. Mater. 2021, 409, 124517.

16. Moravcová, D.; Planeta, J.; King, A.W.; Wiedmer, S.K. Immobilization of a phosphonium ionic liquid on a silica monolith for hydrophilic interaction chromatography. J. Chromatogr. A 2018, 1552, 53-59. [CrossRef] [PubMed]

17. Kulacki, K.J.; Lamberti, G.A. Toxicity of imidazolium ionic liquids to freshwater algae. Green Chem. 2007, 10, 104-110. [CrossRef]

18. Biczak, R.; Pawłowska, B.; Bałczewski, P.; Rychter, P. The role of the anion in the toxicity of imidazolium ionic liquids. J. Hazard. Mater. 2014, 274, 181-190. [CrossRef] 
19. Wang, J.; Shi, D.F.; Zheng, M.Z.; Ma, B.; Cui, J.; Liu, C.M. Screening, separation, and evaluation of xanthine oxidase inhibi-tors from Paeonia lactiflora using chromatography combined with a multi-mode microplate reader. J. Sep. Sci. 2017, 40, 4160-4167. [CrossRef]

20. Fang, Y.-X.; Song, H.-P.; Liang, J.-X.; Li, P.; Yang, H. Rapid screening of pancreatic lipase inhibitors from Monascus-fermented rice by ultrafiltration liquid chromatography-mass spectrometry. Anal. Methods 2017, 9, 3422-3429. [CrossRef]

21. Liu, M.; Huang, X.; Liu, Q.; Li, X.; Chen, M.; Zhu, Y.; Chen, X. Separation of $\alpha$-glucosidase inhibitors from Potentilla kleiniana Wight et Arn using solvent and flow-rate gradient high-speed counter-current chromatography target-guided by ul-trafiltration HPLC-MS screening. Phytochem. Anal. 2019, 30, 661-668. [CrossRef] [PubMed]

22. Yang, X.-W.; Han, M.-H.; Jin, Y.-P. Studies on the chemical constituents from herba anoectochili. J. Chin. Med. Mater. 2007, 30, 797-800.

23. Salimuzzaman, S.; Farrukh, H.; Sabira, B.; Siddiqui, B.S. Oleanderol, a new pentacyclic triterpene from the leaves of Nerium oleander. J. Nat. Prod. 1988, 51, 229-233.

24. Kaur, A.; Singh, N.; Bhatti, M.S.; Bhatti, R. Optimization of extraction conditions of Angelica archangelica extract and activity evaluation in experimental fibromyalgia. J. Food Sci. 2020, 85, 3700-3710. [CrossRef] [PubMed]

25. Medfai, W.; Contreras, M.D.M.; Lama-Muoz, A.; Mhamdi, R.; Castro, E. How cultivar and extraction conditions affect antioxidants type and extractability for olive leaves valorization. ACS Sustain. Chem. Eng. 2020, 8, 5107-5118. [CrossRef]

26. Islam, M.N.; Jo, Y.-T.; Jeong, Y.-J.; Park, J.-H. Remediation approach for organic compounds and arsenic co-contaminated soil using the pressurized hot water extraction process. Environ. Technol. 2017, 40, 125-131. [CrossRef] [PubMed]

27. Noorshamsiana, A.W.; Eliyanti, A.O.N.; Fatiha, I.; Astimar, A.A. A review on extraction process of lignocellulosic chemicals from oil palm biomass. J. Oil Palm Res. 2017, 29, 512-527.

28. Volpp, M.; Holzgrabe, U. Determination of plasma protein binding for sympathomimetic drugs by means of ultrafiltration. Eur. J. Pharm. Sci. 2019, 127, 175-184. [CrossRef]

29. Hou, W.; Li, S.; Li, S.; Shi, D.; Liu, C. Screening and isolation of cyclooxygenase-2 inhibitors fromTrifolium pratense L. via ultrafiltration, enzyme-immobilized magnetic beads, semi-preparative high-performance liquid chromatography and high-speed counter-current chromatography. J. Sep. Sci. 2019, 42, 1133-1143. [CrossRef]

30. Li, S.N.; Tang, Y.; Liu, C.M.; Li, J.; Guo, L.P.; Zhang, Y.C. Development of a method to screen and isolate potential xanthine oxidase inhibitors from Panax japlcus var via ultrafifiltration liquid chromatography combined with counter-current chromatography. Talanta 2015, 134, 665-673. [CrossRef] 